\title{
How to Deal with Ethical Issues Involving Animal Experiments and Identifiable Photographs in Articles Published in Archives of Plastic Surgery
}

Sun Huh

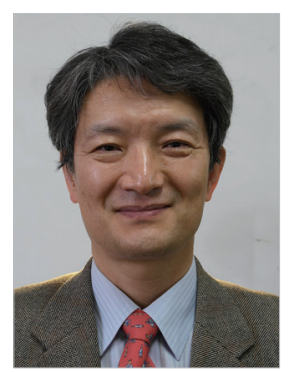

Ethics Editor, Archives of Plastic Surgery

Department of Parasitology and Institute of Medical Education, Hallym University College of Medicine, Chuncheon, Korea

Archives of Plastic Surgery (APS) adheres to the guidelines and best practices published by the appropriate professional organizations, including the Recommendations for the Conduct, Reporting, Editing, and Publication of Scholarly Work in Medical Journals (http://www.icmje.org/icmje-recommendations.pdf) of the International Committee of Medical Journal Editors and the Principles of Transparency and Best Practice in Scholarly Publishing (joint statement by the Committee on Publication Ethics, Directory of Open Access Journals, World Association of Medical Editors, and the Open Access Scholarly Publishers Association; http://doaj.org/bestpractice/).

Recently, APS published "Corrigenda: Omission of the Description of Informed Consent on the Identifiable Photos and the Description on Ethical Treatment of Experimental Animals" [1]. These corrigenda contain a re-description of some ethical issues regarding informed consent and animal experiment ethics in 5 original articles and 3 case reports published in APS from January to September 2017. In the 5 original articles, there was no mention of informed consent despite the presence of an identifiable photograph. Moreover, there was no description of the ethical treatment of all experimental animals in 3 case reports, in which the subjects were chickens or mice.

APS has always verified the provision of informed consent in articles about human subjects or materials originating from humans. The editorial office confirmed the informed consent documents obtained by the authors of the abovementioned 5 original articles. It was a mistake of the editorial office and ethics edi- tor not to screen the main texts for a description of informed consent. Therefore, the corrigenda comprise the re-description of the receipt of informed consent. Second, I found that the statement of animal ethics was not described in the text of 3 articles involving animal experimentation published in 2017. The editorial office contacted the corresponding authors of those 3 articles and learned that the chickens used in the experiments of 2 articles were purchased from a market, and that in the remaining article, the mice were treated according to the animal ethics guidelines of the affiliated institution after receiving permission from the Animal Ethics Committee. Animal materials purchased as food from a market are not subject to regulations regarding ethical treatment. In the 8 articles in question, these ethical issues were re-described appropriately in the published corrigenda.

Obtaining informed consent from patients described in a case report is mandatory if there is an identifiable photograph. Even if no identifiable photograph is presented, it is still recommended to obtain informed consent.

In Korea, the Laboratory Animal Act was officially announced on January 18, 2010 and went into force on March 18, 2010. Furthermore, the Animal Protection Act was officially announced in August 4, 2011 and went into force on February 2, 2012 [2]. Therefore, all animal experiment laboratories in Korea should follow the national or institutional guidelines for the care and use of laboratory animals. Manuscripts from all over the world should be also within the appropriate boundaries of 
Fig. 1. Citation frequency in three kinds of databases

Total citations of Archives of Plastic Surgery from Crossref, Web of Science, and ScimagoJR [cited 2017 Oct 25].

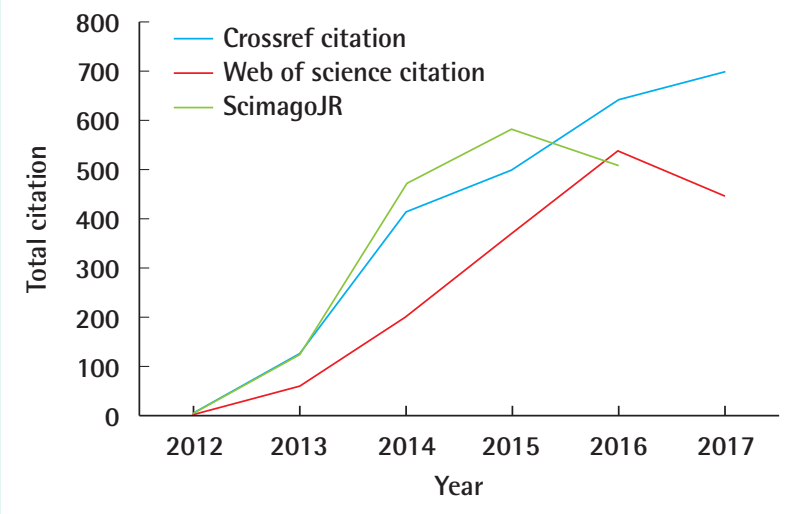

animal experiment ethics. Starting in the September issue, a more rigorous screening process was put in place for ethical issues, ensuring that articles contained clear descriptions of these points.

I believe that APS is one of the best open-access journals in the field of plastic surgery. In particular, it provides the feature of checking for updates (CrossCheck) [3], a funder registry (FundRef) [4], Crossref text and data mining [5], and translation into 80 languages through Google Translate in the ScienceCentral platform [6]. The video clips in APS have been very useful for plastic surgeons to understand the articles more vividly. The content of APS has been invaluable in the practice and research of plastic surgeons, as shown by the citation data in Fig. 1, which documents a tremendous and rapid increase in the number of citations by other journals included in the Crossref metadata [7], the Web of Science Core Collection, and Scopus. The ethical issues recently encountered and the handling thereof may provide momentum for the journal on its journey towards being a journal of the highest quality. To enforce the ethics policy more vigorously, a checklist for informed consent, permission from the Institutional Review Board, and clinical registration will be added to the e-submission system for research on human subjects. Additionally, a checklist for permission from the animal ethics committee and to confirm that experimental animals were treated according to the appropriate guidelines for the care and use of laboratory animals will be added to the e-submission system for studies involving animal experiments.
As the ethics editor, I apologize to our authors and readers for not checking this ethical issue more meticulously. I, the manuscript editor, and the staff of the editorial office will continuously do our best to establish more concrete standards for research ethics in manuscripts submitted to APS.

\section{CONFLICT OF INTEREST}

No potential conflict of interest relevant to this article was reported.

\section{ORCID}

Sun Huh https:/ /orcid.org/0000-0002-8559-8640

\section{REFERENCES}

1. Editorial Office, Archives of Plastic Surgery. Corrigenda: Omission of the description of informed consent on the identifiable photos and the description on ethical treatment of experimental animals. Arch Plast Surg 2017;44:575-6.

2. Korea Ministry of Government Legislation. Animal Protection Act [Internet]. Seoul (KR): The Legislation; c2017 [cited Oct 25, 2017]. Available from: http://www.law. go.kr/eng/engMain.do.

3. Lammey R. CrossRef tools for small publishers. Sci Ed 2015;2:79-85.

4. Lammey R. How to apply CrossMark and FundRef via CrossRef extensible markup language. Sci Ed 2014;1:84-90.

5. Lammey R. CrossRef text and data mining services. Sci Ed 2015;2:22-7.

6. Cho Y, Huh S. Analysis of visits to ScienceCentral, an open access full-text archive of scientific society journal literature. Sci Ed 2017;4:30-3.

7. Lammey R. Using the Crossref Metadata API to explore publisher content. Sci Ed 2016;3:109-11.

Correspondence: Sun Huh

Department of Parasitology and Institute of Medical Education, Hallym University College of Medicine, 1 Hallimdaehak-gil, Chuncheon 24252, Korea

Tel: +82-33-248-2652, Fax: +82-33-241-6765, E-mail: shuh@hallym.ac.kr

Received: 25 Oct 2017 • Revised: 28 0ct 2017 • Accepted: 30 Oct 2017

pISSN: 2234-6163 • elSSN: 2234-6171

https://doi.org/10.5999/aps.2017.01578 • Arch Plast Surg 2017;44:475-476 